\title{
NTCP gene polymorphisms and hepatitis B virus infection status in a Ghanaian population
}

\author{
Eric Nyarko', Christian Obirikorang ${ }^{*}$, W. K. B. A. Owiredu', Evans Asamoah Adu', Emmanuel Acheampong 1,4,
} Freeman Aidoo ${ }^{1}$, Emmanuel Ofori ${ }^{1}$, Bright Selorm Addy ${ }^{3}$ and Henry Asare-Anane ${ }^{2}$

\begin{abstract}
Background: SLC10A1 gene codes NTCP, a receptor through which the hepatitis B virus (HBV) gets access into hepatocytes - a stage of the viral cycle necessary for replication. Polymorphism variants of SLC10A1 play roles in HBV infection, viral clearance, treatment outcome, and complications, in diverse ethnic groups and countries. However, no such study has been conducted in the Ghanaian population, a country with HBV endemicity. Therefore, an exploratory study was conducted to investigate the presence of three (3) single nucleotide polymorphisms (SNPs) in the SLC10A1 gene (rs2296651, rs61745930, and rs4646287) and assessed the risk of HBV infection among the Ghanaian population.
\end{abstract}

Method: Polymerase chain reaction-restriction fragment length polymorphism (PCR-RFLP) method was used to determine the presence of the SNPs among 292 participants comprising $146 \mathrm{HBV}$ infected persons as case-subjects and $146 \mathrm{HBV}$ non-infected persons as control-subjects.

Results: The minor allele frequency (T) of rs 2296651 was present in a significantly high proportion of cases compared with the control group (11.6\% vs. 3.1\%, $p<0.0001)$. The homozygote recessive variant of rs61745930 was present in $2.7 \%$ of the control group and $5.5 \%$ of the case group. Moreover, the minor allele frequencies of rs4646287 were 9.3 and $8.2 \%$ among the control and the case group, respectively ( $p=0.767$ ). Under the dominant (CC) genetic model of inheritance, rs2296651 was found to be protective of HBV infection [OR $=0.18(0.07-0.44)]$, whereas under the co-dominant and additive model, rs2296651 was a potential risk factor for HBV infection [OR = 5.2 (95\%Cl: 2.1-12.8); 3.5 (95\%Cl: 1.6-7.6], respectively. Variants of rs61745930 and rs4646287 were not associated with HBV infection $(p>0.05)$. Polymorphisms in SLC10A1, however, did not show any significant association with HBV infectivity $(p>0.05)$.

Conclusion: The study highlights some polymorphism proof that variants rs2296651, rs61745930, and rs4646287 exist in HBV-infected individuals in Ghana. Although variant rs2296651 was found to be associated with HBV infection, this association warrants more studies. Polymorphisms in SLC10A1 were not associated with HBV infectivity among the Ghanaian population. Further investigation is warranted to assess the offensive role of the relationship between rs2296651 and HBV infectivity.

Keywords: SLC10A1, NTCP, SNP, CHB infection, PCR-RFLP

\footnotetext{
* Correspondence: krisobiri@yahoo.com

'Department of Molecular Medicine, School of Medicine and Dentistry| Kwame Nkrumah University of Science and Technology, Kumasi, Ghana

Full list of author information is available at the end of the article
}

C C The Author(s). 2020 Open Access This article is licensed under a Creative Commons Attribution 4.0 International License, which permits use, sharing, adaptation, distribution and reproduction in any medium or format, as long as you give appropriate credit to the original author(s) and the source, provide a link to the Creative Commons licence, and indicate if changes were made. The images or other third party material in this article are included in the article's Creative Commons licence, unless indicated otherwise in a credit line to the material. If material is not included in the article's Creative Commons licence and your intended use is not permitted by statutory regulation or exceeds the permitted use, you will need to obtain permission directly from the copyright holder. To view a copy of this licence, visit http://creativecommons.org/licenses/by/4.0/ The Creative Commons Public Domain Dedication waiver (http://creativecommons.org/publicdomain/zero/1.0/) applies to the data made available in this article, unless otherwise stated in a credit line to the data. 


\section{Introduction}

The prevalence of hepatitis B virus (HBV) infection in regions of high endemicity ranges from 6 to $8 \%$; in Africa, prevalence rates of $10-15 \%$ have been reported $[1,2]$. Within the adult population in Ghana, prevalence rates between 10 and 13\% have been recorded across the ten regions with a national average rate of $12.3 \%$ [3], which is about $50 \%$ higher than the current global average. This predisposes at least 1/10th of every Ghanaian adult to the risk of later suffering or even dying from HBV- associated complications such as cirrhosis or Hepatocellular carcinoma (HCC) [4, 5]. HBV infection, progression, and complications are affected by factors such as genes, race, gender, age, and expression of some biomolecules such as $\mathrm{CD}^{+}$T-helper cells [6]. Spontaneous clearance of $\mathrm{HBV}$ infection is associated with vigorous polyclonal and multi-specific $\mathrm{CD} 4^{+} \mathrm{T}$-helper cell response, compared to the weak responses observed in persistent or chronic infections [7]. Solute carrier family 10 A1 (SLC10A1) gene-coded $\mathrm{Na}^{+}$-taurocholate cotransporting polypeptide (NTCP) is another molecule that influences the outcome of HBV infection. It is a protein receptor through which the HBV gets access into the hepatocytes, a stage of the viral cycle necessary for replication $[8,9]$. Thus, NTCP could represent a molecular and pharmacologic target for treatment and prevention.

With the high risk of HBV infection and its associated end-stage liver complications, the lack of a cure for HBV infection, high treatment cost $[10,11]$, low long term benefits and high toxicity associated with interferon, nucleoside and nucleotide therapies; new treatments and methods targeting different molecules are warranted. Single nucleotide polymorphic (SNP) variants of the NTCP gene - SLC10A1 such as rs7154439, rs4646287 $[4,12,13]$, rs2296651 and rs61745930 [14-16] is associated with HBV persistent infection (chronicity), expression of $\mathrm{HBeAg}$ and viral clearance among different ethnic groups and countries. The polymorphic SNP variants in the Ghanaian population or responsible for any of the HBV infection status are non-existent. Therefore, this explorative study was conducted to determine the presence three (3) SNPs in the SLC10A1 gene (rs2296651, rs61745930, and rs4646287) and the risk of HBV infection among the Ghanaian population.

\section{Methods}

\section{Study design and participant selection}

This was a case-control study. Two hundred and ninetytwo (292) participants comprising $146 \mathrm{HBV}$ infected persons as cases (excluding active hepatitis B cases) and 146 apparent healthy HBV non-infected persons as controls were recruited from the Greater Accra Region of Ghana
All the participants selected were Ghanaians by birth between 18 and 65 years of age.

\section{Sample size justification}

The sample size for the study was calculated using the Cochran-Armitage trend tests [17]. By considering the additive genetic model at a case: control ratios of $1: 1$, the rare allele frequency (0.079) of the most replicated SNP (rs2296651), and a national HBV average prevalence of $12.3 \%$ [3], the sample size needed to achieve the prespecified $0.05 \alpha$-level and a power 80 for a two-sided trend test was 348 (174 cases vs 174 controls). The total response rate of the participants was approximately $84.0 \%(292 / 348)$. The final population of the study constituted 292 participants comprising of 146 cases and 146 controls.

Sample collection, preparation, biochemical analysis, and DNA isolation

Nine (9) millilitres of venous blood was drawn from each participant into a $3 \mathrm{ml}$ serum separator gel tube (SST) and two $3 \mathrm{ml}$ EDTA tubes; thus, one for haematology and the other for DNA extraction. This was done to avoid contamination. The SST sample was allowed to clot and centrifuged at $2500 \mathrm{~g}$ for $7 \mathrm{mins}$ to obtain serum and preserved between -16 to $-20^{\circ} \mathrm{C}$ till assayed. Mindray 5parts hematology analyzer (Mindray, Shenzhen-China, 2013) was used to quantify blood hemoglobin, blood cells and other cellular indices one EDTA sample, using the impedance, flow cytometry, and vis -spectrophotometry methods depending on the analyte or index (Mindray, 2013, 2018). HumaStar 200 Clinical chemistry analyzer (Human Diagnostics worldwide, Germany, 2014) was used to quantify the concentrations of total and direct bilirubin, total protein, albumin; and the activity of the enzymes: alanine aminotransferase (ALT), aspartate aminotransferase (AST), gamma-glutamyl transferase ( ( $\mathrm{GT}$ ) and alkaline phosphatase (ALP) (Human Diagnostics worldwide, Germany, 2014, 2018). Genomic (g) DNA was isolated from the other EDTA anticoagulated sample as described by Suguna, et al. [18], and preserved below $-80^{\circ} \mathrm{C}$ until genotyped.

\section{Profiling of HBV antigens and HBV -host antibodies}

The commercial Clinogen HBV-5 card was used to screen for the presence of two (2) HBV viral antigens and three (3) host antibodies using colloidal gold and membrane chromatography technology (Clinogen Diagnostics, Japan) after 'running' HBV profile on ELISAconfirmed controls previously obtained from the Noguchi Memorial Institute for Medical Research (NMIMR), Legon, Accra. HBsAg, HBeAg, and HBsAb were screened for with the Immunochromatographic (dualantibody sandwich) principle, and the HBeAb and 
$\mathrm{HBcAb}$ were screened for by the neutralization competitive inhibition principle (Clinogen Diagnostics, Japan; Clinogen Diagnostics, UK).

\section{Primer design}

Primers spanning each of the SNP variants (rs2296651, rs61745930, and rs4646287) were designed using the NCBI Primer-BLAST software and the results shown in Table S1 (https://www.ncbi.nlm.nih.gov/tools/primerblast/index.cgi). Table S1 shows PCR primers and their characteristics restriction enzymes.

\section{Genotyping \\ $P C R$ conditions}

To detect the presence of the rs2296651 (about $200 \mathrm{bp}$, 80), rs61745930 (about $400 \mathrm{bp}, 250 \mathrm{bp}$ ), and rs 4646287 (about $140 \mathrm{bp}, 250$ ) fragments, a $25 \mu \mathrm{L}$ PCR reaction volume consisting of $8.5 \mu \mathrm{L}$ nuclease-free water, $1 \mu \mathrm{L}$ $(10 \mu \mathrm{M})$ each of forward and reverse primers, $12.5 \mu \mathrm{L}$ of One Taq 2x PCR Master mix (New England BioLabs (NEB), USA) and $2 \mu \mathrm{L}$ of the isolated genomic DNA was prepared. Nuclease free water was used in place of the gDNA in the negative control. PCR amplification was done using the Applied Biosystems thermal cycler (Fisher Scientific, USA). Denaturation was completed at $94^{\circ} \mathrm{C}$ for 3 mins (initial) and $94^{\circ} \mathrm{C}$ for $30 \mathrm{~s}$ (on rest). Annealing conditions for rs2296651, rs61745930 and rs4646287 were $58^{\circ} \mathrm{C}(30 \mathrm{~s}), 59.5^{\circ} \mathrm{C}(35 \mathrm{~s})$ and $60.0^{\circ} \mathrm{C}$ $(30 \mathrm{~s})$, respectively. Initial and final extension were completed at $72^{\circ} \mathrm{C}(30 \mathrm{~s})$ and $72^{\circ} \mathrm{C}(10 \mathrm{mins})$, respectively. The denaturation, annealing and extension steps were done for 35 cycles, and the hold after the final extension was at $4{ }^{\circ} \mathrm{C}$.

\section{Restriction digestion}

The optimal enzyme concentration was prepared with the appropriate assay buffer containing $1 \mu \mathrm{g}$ of substrate DNA according to Manufacturer's instructions. Controls were included to ensure there was no contamination or unspecific product obtained. To complete the genotyping of rs $2296651,15 \mu \mathrm{L}$ of the PCR product was added to $0.2 \mu \mathrm{L}$ of $H p h I$ enzyme (NEB, USA) and dissolved in $1.5 \mu \mathrm{L}$ of NEB buffer and $3.3 \mu \mathrm{L}$ of nuclease-free water, and incubated at $37{ }^{\circ} \mathrm{C}$ for $11 \mathrm{~min}$ for the enzyme digestion of the PCR product. Similarly, $15 \mu \mathrm{L}$ of the PCR product was either added to $0.2 \mu \mathrm{L}$ of $B s a B I$ or $0.2 \mu \mathrm{L}$ of Taq I enzymes (NEB, USA) and dissolved in $1.5 \mu \mathrm{L}$ of NEB buffer and $3.3 \mu \mathrm{L}$ of nuclease-free water and incubated at $60{ }^{\circ} \mathrm{C}$ for $60 \mathrm{~min}(1 \mathrm{~h})$ for the enzyme digestion of either rs61745930 or rs4646287.

\section{Product visualization}

The digested fragments were separated with a $2.5 \%$ $\mathrm{EtBr}$ - incorporated agarose gel at $100 \mathrm{~V}, 2 \mathrm{~A}$ for $90 \mathrm{~min}$, and using the Quick-Load purple 100 bp DNA Ladder (NEB, USA) as the molecular marker (MM) and visualized under UV trans-illuminator. The genotypes were determined according to the band patterns/sizes and in comparison, to the molecular marker (MM) as shown in the supplementary figures. Figure S1, Figure S2 and Figure S3 show the gel bands for the SNP rs2296651, rs61745930, and rs4646287, respectively.

\section{Statistical analysis}

Results obtained were entered into the Statistical Package for the Social Sciences (SPSS), coded, and analyzed using this SPSS (version 23.0). Frequencies were used to represent categorical data and compared using ChiSquare test analysis to compare the genotype and allele frequencies between the groups. Skewed data were compared using the Man-Whitney Test. Normally distributed data were represented with mean \pm standard deviation and compared between groups using the $\mathrm{T}$ test. To test for associations between HBV and every single SNP, logistic regression models were fitted, in which each SNP was presented as a predictor variable whose values were equal to the number of copies of the minor allele $(0,1,2)$ in an additive model, or presence of at least one copy of the minor allele $(0,1)$ in a dominant model or presence of two copies of the minor allele $(0$, 1 ) in a recessive model. Sex, age and family history of HBV status were included as covariates in the fitted model. The structure of the model was represented as: Logit $[\operatorname{pr}(D=1)]=\alpha+\beta 1 \mathrm{G}$.

Where D denotes HBV phenotype; G denotes SNP coded as an additive, dominant or recessive; $\beta$ denotes the corresponding coefficient for each variable in the model, and its exponential is the corresponding odds ratio. A $P$-value of less than 0.05 was considered statistically significant.

\section{Results}

Table 1 shows the comparison of age, gender, biochemical indices between cases and controls. The male and female participants were equivalently distributed among cases and controls $(p=0.193)$. Total protein, direct bilirubin, ALT, ALP and de-Ritis ratio did not show any significant differences between cases and control participants $(p>0.05)$. However, total bilirubin $(p=0.002)$, indirect bilirubin $(p<0.0001)$, and AST $(p=0.007)$ were significantly higher in cases compared with controls. On the other hand, albumin $(p=0.010)$ and GGT $(p=0.042)$ were significantly higher in controls compared with cases. The aspartate aminotransferase-to-platelet ratio index (APRI index) $(p=0.003)$, fibrosis index based on four factors (FIB-4) $(p=0.009)$ and RDW-to-platelet ratio (RPR) $(p<0.0001)$ were significantly higher in the case-subjects compared to control subjects. Table S2 
Table 1 Descriptive summary of demographic and liver function indices of the study participants

\begin{tabular}{|c|c|c|c|}
\hline Variables & $\begin{array}{l}\text { Control } \\
n=146\end{array}$ & $\begin{array}{l}\text { Cases } \\
n=146\end{array}$ & $P$-value \\
\hline Gender $^{a}$ & & & 0.193 \\
\hline Male & 68 (46.6) & $57(39.0)$ & \\
\hline Female & $78(53.4)$ & $89(61.0)$ & \\
\hline Age (years) & $31.3 \pm 10.0$ & $30.6 \pm 8.1$ & 0.542 \\
\hline Total Bilirubin ( $\mu \mathrm{mol} / \mathrm{L})$ & $12.73 \pm 5.29$ & $14.89 \pm 6.56$ & 0.002 \\
\hline Direct Bilirubin ( $\mu \mathrm{mol} / \mathrm{L})$ & $6.59 \pm 3.54$ & $6.44 \pm 3.22$ & 0.700 \\
\hline Indirect Bilirubin $(\mu \mathrm{mol} / \mathrm{L})$ & $6.08 \pm 3.27$ & $8.13 \pm 4.50$ & $<0.0001$ \\
\hline Total protein (g/L) & $72.35 \pm 7.52$ & $70.83 \pm 9.97$ & 0.141 \\
\hline Albumin (g/L) & $41.69 \pm 5.53$ & $39.72 \pm 7.35$ & 0.010 \\
\hline ALT (U/L & $26.42 \pm 11.79$ & $27.33 \pm 13.59$ & 0.540 \\
\hline AST (U/L) & $27.14 \pm 13.30$ & $30.35 \pm 19.10$ & 0.007 \\
\hline GGT (U/L) & $33.37 \pm 16.99$ & $27.72 \pm 12.73$ & 0.042 \\
\hline ALP (U/L) & $159.7 \pm 55.8$ & $159.0 \pm 53$ & 0.914 \\
\hline De Ritis ratio & $1.0(0.80-1.26)$ & $1.03(0.76-1.47)$ & 0.631 \\
\hline APRI index & $0.30(0.20-0.43)$ & $0.37(0.25-0.50)$ & 0.003 \\
\hline FIB-4 & $0.68(0.49-1.05)$ & $0.80(0.60-1.18)$ & 0.009 \\
\hline RPR & $0.06(0.04-0.07)$ & $0.07(0.06-0.10)$ & $<0.0001$ \\
\hline
\end{tabular}

Data is presented as means \pm standard deviation. Variables with the superscript "a" were presented as frequency and subgroup proportions. $A L T$ Alanine aminotransferase, AST Aspartate aminotransferase, GGT Gamma-glutamyl transferase, APRI index Aspartate aminotransferase-to-platelet ratio index, FIB-4 fibrosis index based on four factors, RPR RDW-to-platelet ratio, $P<0.05$ is considered statistically significant

shows the measured hematological parameters among cases and control subjects. Apart from RBC count, MCV, PCT, and hematocrit level $(p>0.05)$, cases and control participants significantly differed in terms of measured hematological parameters.

The genotype and allele frequencies of SLC10A1 gene polymorphism were compared between cases and control participants (Table 2). The minor allele frequency (T) of rs2296651 was presenting in a significantly high proportion of cases compared with the control group (0.116 vs $0.031, p<0.0001)$. Also, the heterozygote $(18.5 \%$ vs $6.2 \%, p=0.001)$ and homozygote recessive $(3.4 \%$ vs $0 \%, p=0.025)$ variants of rs2296651 were present in significantly higher proportions of the case group than the control group, respectively. The homozygote recessive variant of rs61745930 was present in 2.7\% of the control group and 5.5\% of the case group. Moreover, the minor allele frequencies of rs 4646287 were 9.3 and $8.2 \%$ among the control and the case group, respectively $(p=0.767)$ (Table 2$)$.

Table S3 shows the re-categorised into HBeAg positive (active) and HBeAg negative (inactive) based on HBV antigen/antibody profiling. The results indicated that $39.0 \%$ were active $\mathrm{CHB}$ cases whereas $61.0 \%$ were inactive $\mathrm{CHB}$ cases.

The genotype and allele frequencies of SLC10A1 gene polymorphism in active $\mathrm{CHB}$ and inactive $\mathrm{CHB}$ cases are shown in Table 3. There were no significant differences in allele and genotype frequencies among HBeAg positive and HBeAg negative cases $(p>0.05)$ Table 3.

The association between SLC10A1 variants and HBV infection was compared under the recessive, dominant, co-dominant and additive model of inheritance. Under the dominant model, rs2296651 was found to be protective of HBV infection, whereas, under the co-dominant and additive model, rs2296651 was a risk factor for HBV infection (Table 4). Polymorphisms in rs61745930 and rs4646287 were not significantly associated with HBV infection under any of the models (Table 4).

\section{Discussion}

Several studies have reported the presence of SLC10A1 rs2296651, rs61745930, and rs4646287 SNP variants among persons with HBV infection $(4,14,24)$. Thus, we determined the association between 3 SNPs in the SLC10A1 gene (rs2296651, rs61745930, and rs4646287) and the risk of HBV infection among the Ghanaian population. Our results indicated that the MAF of rs2296651 was 3.1\% among HBV uninfected population and $11.6 \%$ among HBV infected population. These findings are similar to those reported among Korean (3.1\%) and Chinese-Americans (7.5\%) populations [14]. Also, similar findings have been replicated among Chinese and Vietnamese in a study by Wang, et al. [13]. Moreover, Li, et al. [15] reported a 4.4\% MAF of rs2296651 
Table 2 Genotype, allele frequencies of SLC10A1 gene polymorphism in the study participants

\begin{tabular}{|c|c|c|c|c|c|c|c|}
\hline \multirow[t]{3}{*}{ SNP } & \multicolumn{3}{|c|}{ Controls $(n=146)$} & \multicolumn{3}{|c|}{ Cases $(n=146)$} & \multirow[t]{3}{*}{${ }^{\dagger} P$-value } \\
\hline & \multirow[t]{2}{*}{ n (\%) } & \multicolumn{2}{|c|}{ Allele frequency } & \multirow[t]{2}{*}{$\mathrm{n}(\%)$} & \multicolumn{2}{|c|}{ Allele frequency } & \\
\hline & & $C$ & $\mathrm{~T}$ & & $\mathrm{C}$ & $\mathrm{T}$ & \\
\hline rs2296651 & & 0.969 & 0.031 & & 0.884 & 0.116 & $<0.0001$ \\
\hline $\mathrm{CC}$ & 137 (93.8) & & & $114(78.1)$ & & & 0.0001 \\
\hline $\mathrm{CT}$ & $9(6.2)$ & & & $27(18.5)$ & & & 0.001 \\
\hline$\pi$ & $0^{\mathrm{a}}$ & & & $5(3.4)$ & & & 0.025 \\
\hline$H W E-P^{\ddagger}$ & 1.00 & & & 0.112 & & & \\
\hline rs61745930 & & 0.014 & 0.986 & & 0.028 & 0.972 & 0.238 \\
\hline$\pi$ & $142(97.3)$ & & & $138(94.5)$ & & & 0.228 \\
\hline $\mathrm{CT}$ & 0 & & & 0 & & & - \\
\hline $\mathrm{CC}$ & $4(2.7)$ & & & $8(5.5)$ & & & 0.228 \\
\hline$H W E-P^{\ddagger}$ & 0.003 & & & 0.009 & & & 0.888 \\
\hline rs4646287 & & 0.907 & 0.093 & & 0.918 & 0.082 & 0.767 \\
\hline $\mathrm{CC}$ & $120(82.2)$ & & & $123(84.2)$ & & & 0.648 \\
\hline $\mathrm{CT}$ & $24(16.4)$ & & & $21(14.4)$ & & & 0.636 \\
\hline$\pi$ & $2(1.4)$ & & & $2(1.4)$ & & & 1.00 \\
\hline$H W E-P^{ \pm}$ & 0.763 & & & 0.549 & & & \\
\hline
\end{tabular}

Cases: HBV seropositive, Controls: HBV seronegative, HWE-P Hardy-Weinberg equation $p$-values, ${ }^{\dagger} P$-values represents the chi-square test to compare genotype frequency between case-and control -subjects. $P$-values for chi-squared test for variant allelic frequency based on HWE, $p<0.05$ depicts it not consistent with HWE

Table 3 Genotype, allele frequencies of SLC10A1 gene polymorphism in active and inactive cases

\begin{tabular}{|c|c|c|c|c|c|c|c|}
\hline \multirow[t]{3}{*}{ SNP } & \multicolumn{3}{|c|}{ Inactive CHB cases $(n=89)$} & \multicolumn{3}{|c|}{ Active CHB cases $(n=57)$} & \multirow[t]{3}{*}{${ }^{\dagger} P$-value } \\
\hline & \multirow[t]{2}{*}{ N (\%) } & \multicolumn{2}{|c|}{ Allele frequency } & \multirow[t]{2}{*}{ N (\%) } & \multicolumn{2}{|c|}{ Allele frequency } & \\
\hline & & $\mathrm{C}$ & $T$ & & $\mathrm{C}$ & $T$ & \\
\hline rs2296651 & & 0.882 & 0.118 & & 0.860 & 0.140 & 0.240 \\
\hline $\mathrm{CC}$ & $72(80.9)$ & & & $42(73.7)$ & & & \\
\hline $\mathrm{CT}$ & $13(14.6)$ & & & $14(24.6)$ & & & \\
\hline$\pi$ & $4(4.5)$ & & & $1(1.8)$ & & & \\
\hline HWE- $P^{\ddagger}$ & 0.123 & & & 0.112 & & & \\
\hline rs61745930 & & 0.044 & 0.956 & & 0.035 & 0.965 & 0.382 \\
\hline$\pi$ & $85(95.5)$ & & & $53(93.0)$ & & & \\
\hline $\mathrm{CT}$ & 0 & & & 0 & & & \\
\hline CC & $4(4.5)$ & & & $4(7.0)$ & & & \\
\hline HWE- $P^{\ddagger}$ & & 0.013 & & & 0.009 & & \\
\hline rs4646287 & & 0.916 & 0.084 & & 0.912 & 0.088 & 0.374 \\
\hline $\mathrm{CC}$ & $76(85.4)$ & & & $47(82.5)$ & & & \\
\hline$C T$ & $11(12.4)$ & & & $10(17.5)$ & & & \\
\hline$\pi$ & $2(2.2)$ & & & 0 & & & \\
\hline$H W E-P^{\ddagger}$ & 0.615 & & & 0.821 & & & \\
\hline
\end{tabular}

HWE-P Hardy-Weinberg equation $\mathrm{p}$-values, ${ }^{\dagger} \mathrm{P}$-values represents the chi-square test to compare genotype frequency between case-and control -subjects. $P$-values for chi-squared test for variant allelic frequency based on HWE, $p<0.05$ depicts it not consistent with HWE 
Table 4 Odds ratios and P-values of SLC10A1 gene polymorphism under recessive, dominant, co-dominant and additive models of inheritance

\begin{tabular}{|c|c|c|c|}
\hline Model & Alleles & $\mathrm{aOR}(95 \% \mathrm{Cl})$ & bOR $(95 \% \mathrm{Cl})$ \\
\hline \multicolumn{4}{|l|}{ rs2296651 } \\
\hline \multirow[t]{2}{*}{ Recessive Model } & $\mathrm{mt} / \mathrm{wt} C T+\mathrm{wt} / \mathrm{wt} T \mathrm{~T}$ & 1 (reference) & 1 (reference) \\
\hline & $\mathrm{mt} / \mathrm{mt} \mathrm{CC}$ & $\mathrm{n} / \mathrm{a}$ & $2.70(0.29-24.78)$ \\
\hline \multirow[t]{2}{*}{ Dominant Model } & $\mathrm{mt} / \mathrm{wt} \mathrm{TC}+\mathrm{mt} / \mathrm{mt} T$ & 1 (reference) & 1 (reference) \\
\hline & wt/wt CC & $0.18(0.07-0.44) *$ & $1.55(0.70-3.43)$ \\
\hline \multirow[t]{2}{*}{ Co-dominant model } & $\mathrm{wt} / \mathrm{wt} \mathrm{CC}+\mathrm{mt} / \mathrm{mt} T$ & 1 (reference) & 1 (reference) \\
\hline & $\mathrm{mt} / \mathrm{wt} \mathrm{TC}$ & $5.2(2.1-12.8) *$ & $0.85(0.4-1.6)$ \\
\hline \multirow[t]{2}{*}{ Additive model 1} & $\mathrm{mt} / \mathrm{wt} \mathrm{TC}$ & 1 (reference) & 1 (reference) \\
\hline & $\mathrm{mt} / \mathrm{mt} \mathrm{TT}$ & $5.23(2.09-13.11) *$ & $0.49(0.20-1.16)$ \\
\hline \multicolumn{4}{|l|}{ rs61745930 } \\
\hline \multirow[t]{2}{*}{ Additive Model } & wt/wt TT & 1 (reference) & 1 (reference) \\
\hline & $\mathrm{mt} / \mathrm{mt} \mathrm{CC}$ & $1.5(0.7-3.2)$ & $0.80(0.4-1.6)$ \\
\hline \multicolumn{4}{|l|}{ rs4646287 } \\
\hline \multirow[t]{2}{*}{ Recessive Model } & $\mathrm{mt} / \mathrm{wt} \mathrm{TC}+\mathrm{wt} / \mathrm{wt} T \mathrm{~T}$ & 1 (reference) & 1 (reference) \\
\hline & $\mathrm{mt} / \mathrm{mt} \pi$ & $n / a$ & $\mathrm{n} / \mathrm{a}$ \\
\hline \multirow[t]{2}{*}{ Dominant Model } & $\mathrm{mt} / \mathrm{wt} \mathrm{TC}+\mathrm{mt} / \mathrm{mt} T$ & 1 (reference) & 1 (reference) \\
\hline & wt/wt CC & $0.81(0.35-1.85)$ & $1.31(0.53-3.24)$ \\
\hline \multirow[t]{2}{*}{ Co-dominant model } & $\mathrm{wt} / \mathrm{wt} \mathrm{CC}+\mathrm{mt} / \mathrm{mt} T$ & 1 (reference) & 1 (reference) \\
\hline & $\mathrm{mt} / \mathrm{wt} C \mathrm{~T}$ & $1.10(0.50-2.4)$ & $0.96(0.4-2.2)$ \\
\hline \multirow[t]{2}{*}{ Additive model 1} & $\mathrm{mt} / \mathrm{wt} \mathrm{TC}$ & 1 (reference) & 1 (reference) \\
\hline & $\mathrm{mt} / \mathrm{mt} \pi$ & $1.34(0.58-3.10)$ & $0.65(0.25-1.66)$ \\
\hline
\end{tabular}

$m t$ mutant type, wt wild type, Highlighted values represent statistically significant values. Cl-confidence interval; “*” represent statistically significant model, $\mathrm{p} \mathrm{f}<$ 0.05. aOR- odds ratios for controls vs cases; bOR- odds ratios HBeAg positive and HBeAg negative

among the Chinese Han population. In a more recent study among Vietnamese, the rs2296651 variant was reported in an average of $6 \%$ of the population, with a $\mathrm{T}$ minor allele frequency of $3 \%$ [19].

Also, the distribution of the MAF of rs61745930 and rs4646287 were 1.4 and 9.3\% among HBV uninfected population, and 2.8 and $8.2 \%$ among $\mathrm{HBV}$ infected population. Variants of rs4646287 had the highest frequency among the study participants, with about 16.4 and $1.4 \%$ of the Ghanaian HBV uninfected population carrying the codominant (CT) and recessive (TT) variants, respectively. Lower frequencies of the variant than these were observed among the Chinese Han [20] and Chinese [21] population. Also, Chuaypen, et al. [22] reported rs 4646287 average MAF of $17.3 \%$ among the Thai population with CT and TT genotype frequencies of 16 and $1.3 \%$ respectively and the $\mathrm{T}$ minor allele was found to be $9.3 \%$. These findings indicate that the rs2296651, rs61745930, and rs4646287 SLC10A1 polymorphisms -its genotypes and alleles- are widely distributed among Asians and the Ghanaian population. However, some studies have reported the absence or low prevalence of these SLC10A1 SNP variants in Caucasians [23]. Thus, replication studies among a wider population of Ghanaians and the entire of
Africa are warranted since these countries represent HBV endemic territories.

We observed that variants of rs2296651 were associated with the risk of HBV infection. However, the association was independent of HBV infectivity. Under the recessive, additive and codominant model of inheritance, we observed that rs2296651 was associated with the increased risk of HBV infection. On the other hand, under the dominant genetic inheritance model, we observed that rs2296651 was protective of HBV infection. Several studies have indicated that variants of rs2296651 either increases an individual's susceptibility to HBV infection and/or its complications, makes resolution/viral clearance of the infection faster or improves the prognostic outcome of cirrhosis and HCC $[15,19-22]$. The evidence of the transferability of rs2296651 associated with HBV infection has been demonstrated among the Han population [15], Taiwanese [24] and Vietnamese [19]. However, unlike our results, rs2296651 [ $($ c.800C $>\mathrm{T})$ (S267F)] has been associated with reduced HBV infection and associated hepatic complications [25]. Among the population of Thailand, the rs2296651 SNP variant was associated with inactive and non-infectious $\mathrm{CHB}$ and viral clearance among HBV infected persons [22]. 
These findings indicate that although variants of rs2296651 are associated with HBV infection, the definition of the risk variant may be dependent on the genetic architecture of the population as well as the environmental agents identified as risk factors for HBV infection.

The study has some limitations that should be acknowledged. The sample of the study was small which may affect power replication of the odds of NTCP polymorphic variants associated with HBV infection. Also, the study was localized, and generalization of findings should be done with caution, and therefore recommend replication studies in other parts of the country considering the limitation of this study. Although further studies are required, we have demonstrated the feasibility of the association of rs2296651 with HBV infection in the Ghanaian population and our findings are congruent with previous reports among the Asian populations.

\section{Conclusion}

The study highlights some polymorphism proof that variants of rs2296651, rs61745930, and rs4646287 exist in HBV-infected individuals in Ghana. Although, variant rs2296651 was found to be associated with HBV infection. Polymorphisms in SLC10A1 is not associated with HBV infectivity among the Ghanaian population. Further investigation is warranted to assess the predisposition role of the relationship between rs2296651 and HBV infectivity.

\section{Supplementary information}

Supplementary information accompanies this paper at https://doi.org/10. 1186/s12985-020-01376-0.

Additional file 1: Table S1. PCR primers and their characteristics restriction enzymes. Table S1 shows the primers spanning each of the SNP variants (rs2296651, rs61745930, and rs4646287) were designed using the NCBI Primer-BLAST software. Table S2. Hematological profile of the study participants. Table $\mathbf{S} 2$ shows the measured hematological parameters among cases and control subjects. Table S3. Antigens and host antibodies profiling of HBV positive cases. Table S3 shows the re-categorised into HBeAg positive (active) and HBeAg negative (inactive) based on HBV antigen/antibody profiling.

Additional file 2: Figure S1. Gel bands for the SNP rs2296651 obtained using the PCR-RFLP. Figure S1 shows the gel bands for the SNP rs2296651 obtained using the PCR-RFLP. MM = the molecular marker or ladder; $\mathrm{NC}=$ the negative control; C (200 bp), T (120 bp). Samples 51-60 are cases and samples 291-300 are controls.

Additional file 3: Figure S2. Gel bands for the SNP rs61745930 obtained using the PCR-RFLP. Figure S2 shows the gel bands for the SNP rs61745930 obtained using the PCR-RFLP. MM = the molecular marker or ladder; $\mathrm{NC}=$ the negative control; $\mathrm{C}(400 \mathrm{bp}), \mathrm{T}(250) . \mathrm{Ca}=\mathrm{Cases}$ and $\mathrm{Co}=$ Controls. Samples 22-25, 27, 30 and 33 are cases and samples 243, 249,252, 318, 320-322 are controls.

Additional file 4: Figure S3. Gel bands for the SNP rs4646287 obtained using the PCR-RFLP. Figure S3 shows the gel bands for the SNP rs4646287 obtained using the PCR-RFLP. MM = the molecular marker or ladder; C (240 bp), T (140). Samples 35-46 are cases; and samples 201205 plus $286-290$ are controls.

\section{Abbreviations}

HBV: Hepatitis B virus; MAF: Minor allele frequency; SNP: Single nucleotide polymorphism; SLC10A1: Solute carrier family 10 A1; NTCP: $\mathrm{Na}^{+}$-taurocholate co-transporting polypeptide; HCC: Hepatocellular carcinoma; PCR-

RFLP: Polymerase chain reaction-restriction fragment length polymorphism

\section{Acknowledgements}

The authors acknowledge the efforts of the entire staff of Mamprobi Polyclinic, Ussher Polyclinic, Kaneshie Polyclinic, Ridge Regional Hospital, and Amasaman Government Hospital. Also, sincere gratitude goes to staff of Noguchi Memorial Institute for Medical Research (NMIMR), Legon, Accra.

\section{Authors' contributions}

CO \& WKBAO were involved in conceptualization, methodology, software, supervision, validation, Writing - original draft, Writing - review \& editing; EN was involved in conceptualization, data curation, formal analysis, supervision, writing - original draft, writing - review \& editing; EA \& EAA contributed in conceptualization, data curation, validation, writing - original draft, writing review \& editing; FA was involved in investigation, writing - original draft, writing - review \& editing; EO was involved in conceptualization, data curation, formal analysis, supervision, writing - original draft, writing - review \& editing; BSA was involved in data curation - review \& editing; HAA was involved in data curation, formal analysis, supervision. The author(s) read and approved the final manuscript.

\section{Funding}

This research did not receive any specific grant from funding agencies in the public, commercial, or not-for-profit sectors.

\section{Availability of data and materials}

The datasets used and/or analysed during the current study are available from the corresponding author on reasonable request.

\section{Ethics approval and consent to participate}

Ethical clearance (Refs: CHRPE/RC/053/18, CHRPE/AP/426/19, GAR/RHD/ ADMIN) was obtained from the Committee of Human Research Publication and Ethics (CHRPE) of the Kwame Nkrumah University of Science and Technology, (KNUST), Kumasi, Ghana and Ghana Health Service (GHS). Written informed consent was obtained from all participants before recruiting them into the study. A consent form was given to each participant to sign or thumbprint and confidentiality were assured.

Consent for publication

Not applicable.

\section{Competing interests}

The authors declare that they have no competing interests.

\section{Author details}

${ }^{1}$ Department of Molecular Medicine, School of Medicine and Dentistry|, Kwame Nkrumah University of Science and Technology, Kumasi, Ghana. 2Department of Chemical Pathology, University of Ghana Medical School, Accra, Ghana. ${ }^{3}$ School of Pharmacy, Central University, Accra, Ghana. ${ }^{4}$ School of Medical and Health Science, Edith Cowan University, Joondalup, Australia.

Received: 16 April 2020 Accepted: 30 June 2020

Published online: 03 July 2020

\section{References}

1. Kim BH, Kim WR. Epidemiology of hepatitis B virus infection in the United States. Clinical liver disease. 2018;12(1):1.

2. Organization WH: Global hepatitis report 2017: World Health Organization; 2017.

3. Ofori-Asenso R, Agyeman AA. Hepatitis B in Ghana: a systematic review \& meta-analysis of prevalence studies (1995-2015). BMC Infect Dis. 2016; 16(1):130.

4. Wang J, Zhao G, Chen J, Xia J, Wang S, Huang G, Chen F, Shi J, Yang Y, Wei Y. Association of hepatitis B infection with high-risk complications in total joint arthroplasty. BMC Musculoskelet Disord. 2019;20(1):163. 
5. Razavi-Shearer D, Gamkrelidze I, Nguyen MH, Chen D-S, Van Damme P, Abbas Z, Abdulla M, Rached AA, Adda D, Aho I. Global prevalence, treatment, and prevention of hepatitis B virus infection in 2016: a modelling study. Lancet Gastroenterol Hepatol. 2018;3(6):383-403.

6. Su Z, Li Y, Liao Y, Cai B, Chen J, Zhang J, Li L, Ying B, Tao C, Zhao M. Polymorphisms in sodium taurocholate cotransporting polypeptide are not associated with hepatitis B virus clearance in Chinese Tibetans and Uygurs. Infect Genet Evol. 2016:41:128-34.

7. Wisskirchen K, Kah J, Malo A, Asen T, Volz T, Allweiss L, Wettengel JM, Lütgehetmann M, Urban S, Bauer T. T cell receptor grafting allows virological control of hepatitis B virus infection. J Clin Invest. 2019; 129(7):2932-45.

8. Yan H, Peng B, Liu Y, Xu G, He W, Ren B, Jing Z, Sui J, Li W. Viral entry of hepatitis $B$ and $D$ viruses and bile salts transportation share common molecular determinants on sodium taurocholate cotransporting polypeptide. J Virol. 2014;88(6):3273-84.

9. Yan H, Liu Y, Sui J, Li W. NTCP opens the door for hepatitis B virus infection. Antivir Res. 2015;121:24-30.

10. Lok AS, Zoulim F, Dusheiko G, Ghany MG. Hepatitis B cure: from discovery to regulatory approval. J Hepatol. 2017;67(4):847-61.

11. Yang $F, W u L, X u$ W, Liu $Y$, Zhen $L$, Ning G, Song J, Jiao Q, Zheng $Y$, Chen $T$. Diverse Effects of the NTCP p. Ser267Phe Variant on Disease Progression During Chronic HBV Infection and on HBV preS1 Variability. Front Cell Infect Microbiol. 2019:9.

12. Yan $H$, Zhong G, Xu G, He W, Jing Z, Gao Z, Huang Y, Qi Y, Peng B, Wang H. Sodium taurocholate cotransporting polypeptide is a functional receptor for human hepatitis B and D virus. elife. 2012;1:e00049.

13. Wang P, Mo R, Lai R, Xu Y, Lu J, Zhao G, Liu Y, Cao Z, Wang X, Li Z. Genetic variations of NTCP are associated with susceptibility to HBV infection and related hepatocellular carcinoma. Oncotarget. 2017;8(62): 105407.

14. Ho RH, Leake BF, Roberts RL, Lee W, Kim RB. Ethnicity-dependent polymorphism in Na+-taurocholate cotransporting polypeptide (SLC10A1) reveals a domain critical for bile acid substrate recognition. J Biol Chem. 2004;279(8):7213-22.

15. Li N, Zhang P, Yang C, Zhu Q, Li Z, Li F, Han Q, Wang Y, LV Y, Wei P. Association of genetic variation of sodium taurocholate cotransporting polypeptide with chronic hepatitis B virus infection. Genet Testing Mol Biomarkers. 2014;18(6):425-9.

16. Pan W, Song I-S, Shin H-J, Kim M-H, Choi Y-L, Lim S-J, Kim W-Y, Lee S-S, Shin J-G. Genetic polymorphisms in Na+-taurocholate co-transporting polypeptide (NTCP) and ileal apical sodium-dependent bile acid transporter (ASBT) and ethnic comparisons of functional variants of NTCP among Asian populations. Xenobiotica. 2011:41(6):501-10.

17. Zheng G, Gastwirth JL. On estimation of the variance in Cochran-Armitage trend tests for genetic association using case-control studies. Stat Med. 2006:25(18):3150-9.

18. Suguna S, Nandal D, Kamble S, Bharatha A, Kunkulol R. Genomic DNA isolation from human whole blood samples by non enzymatic salting out method. Int J Pharm Pharm Sci. 2014;6(6):198-9.

19. Binh MT, Hoan NX, Van Tong H, Sy BT, Trung NT, Bock C-T, Toan NL, Bang MH, Meyer CG, Kremsner PG. NTCP S267F variant associates with decreased susceptibility to HBV and HDV infection and decelerated progression of related liver diseases. Int J Infect Dis. 2019;80:147-52.

20. Su Z, Li Y, Liao Y, Cai B, Chen J, Zhang J, Li L, Ying B, Tao C, Wang L. Association of the gene polymorphisms in sodium taurocholate cotransporting polypeptide with the outcomes of hepatitis B infection in Chinese Han population. Infect Genet Evol. 2014;27:77-82.

21. Yang J, Yang Y, Xia M, Wang L, Zhou W, Yang Y, Jiang Y, Wang H, Qian J, Jin L. A genetic variant of the NTCP gene is associated with HBV infection status in a Chinese population. BMC Cancer. 2016;16(1):211.

22. Chuaypen N, Tuyapala N, Pinjaroen N, Payungporn S, Tangkijvanich P. Association of NTCP polymorphisms with clinical outcome of hepatitis B infection in Thai individuals. BMC Med Genet. 2019;20(1):87

23. Casillas R, Tabernero D, Gregori J, Belmonte I, Cortese MF, González C, Riveiro-Barciela M, López RM, Quer J, Esteban R. Analysis of hepatitis B virus preS1 variability and prevalence of the rs2296651 polymorphism in a Spanish population. World J Gastroenterol. 2018; 24(6):680
24. Nfor O, Wu MF, Debnath T, Lee CT, Lee W, Liu WH, Tantoh D, Hsu SY, Liaw YP. Hepatitis B virus infection in Taiwan: the role of NTCP rs2296651 variant in relation to sex. J Viral Hepat. 2018;25(10):1116-20.

25. Hu H-H, Liu J, Lin Y-L, Luo W-S, Chu Y-J, Chang C-L, Jen C-L, Lee M-H, Lu SN, Wang L-Y. The rs2296651 (S267F) variant on NTCP (SLC10A1) is inversely associated with chronic hepatitis B and progression to cirrhosis and hepatocellular carcinoma in patients with chronic hepatitis B. Gut. 2016; 65(9):1514-21.

\section{Publisher's Note}

Springer Nature remains neutral with regard to jurisdictional claims in published maps and institutional affiliations.

\section{Ready to submit your research? Choose BMC and benefit from:}

- fast, convenient online submission

- thorough peer review by experienced researchers in your field

- rapid publication on acceptance

- support for research data, including large and complex data types

- gold Open Access which fosters wider collaboration and increased citations

- maximum visibility for your research: over $100 \mathrm{M}$ website views per year

At BMC, research is always in progress.

Learn more biomedcentral.com/submissions 